\title{
Research on the Application and Development of Production Technology of Computer Animation in the New Media Environment
}

\author{
Zhang Jinxi ${ }^{{ }^{*}}$, Huang Jianjun \\ Lanzhou University of Finance and Economics, China \\ a582361484@qq.com
}

Keywords: New media; computer animation production technology; application; development. Abstract. With the continuous development of science and technology, the application of new media is becoming more and more extensive, which brings convenience to the development of all walks of life, and to promote the development of the industry, especially its application in computer animation production technology, to a certain extent, it promotes the rapid development of computer animation technology, which make it realizes a qualitative leap, and broaden its development channels. With the continuous development of new media, its form becomes more simple and convenient, which in a certain sense, the promotion of computer animation production technology continues to innovate, and the form is more novel, the platform is more broad, with the network animation and mobile animation as the representative of new media animation has become a new growth point of China's animation industry. This paper discusses the development of computer animation production technology in China, and analyzes the application of the technology in the new media environment, and points out the development trend of computer animation in the new media environment. It can provide a meaningful reference for the relevant teaching, production personnel and the vast number of animation enthusiasts.

\section{The development of computer animation production technology in China}

From 1960s, China's animation industry has begun to 1980s, its development scale in the growing, and its technical level has been greatly improved.

Animation design software continues to introduce new technology, and to promote the development of two-dimensional animation, making it more perfect in image, and its technology is becoming more and more mature. And some new knowledge and technology, after in the process of development and evolution, become a professional technical tools. And some software and hardware developers according to the different needs of the market, to modify software and hardware, to improve, and promote the rapid development of computer animation, into 21th Century, the animation industry is not only growing fast, but also shortens the distance to the public life, animation film industry continues to develop, it results in the continuous improvement of its technology. With the development of science and technology, new media technology, and computer animation technology will both get a great development. As we know, these are 7 domestic animated films that the film box office reached more than 50,000,000 yuan in 2014, as shown in table 1. Compared with 5 in 2013 and only 1 every year in 2010 - 2012, the domestic animation film box office can be described as a good performance in 2014. Figure 1 is comparison about nearly 5 years of domestic animation film box office.

Table 1: box office in 2014 over fifty million domestic animation list (unit: ten thousand yuan)

\begin{tabular}{|c|c|}
\hline The Title & Box Office \\
\hline 《Boonie Bears: To the Rescue》 & 24700 \\
\hline 《Pleasant Goat and Big Big Wolf 6》 & 8751 \\
\hline 《The SEER 6》 & 6231 \\
\hline 《The Secret World Adventures 2》 & 6230 \\
\hline 《The Legend of Qin》 & 5985 \\
\hline 《The Magical Pe》 & 5866 \\
\hline 《Dragon Nest - Warriors'dawn》 & 5753 \\
\hline
\end{tabular}




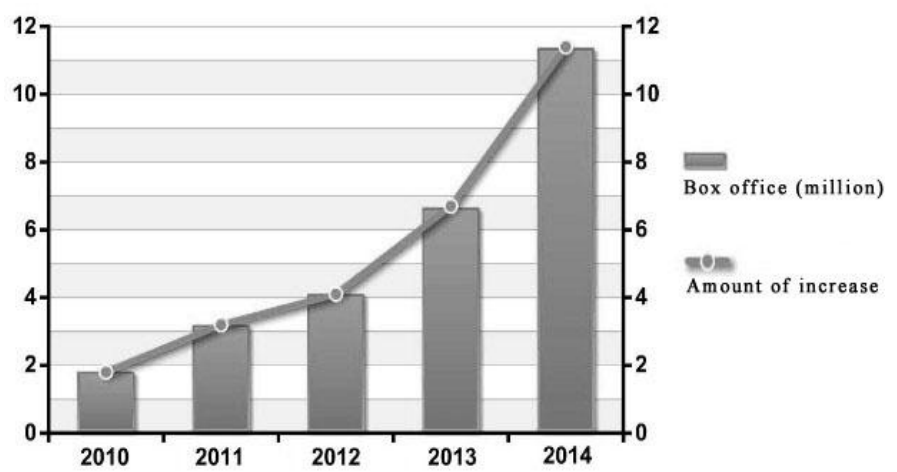

Figure 1 total domestic animation film at the box office for five years

\section{Application of computer animation production technology in new media environment}

To improve the level of science and technology in a certain significance to promote the development of all walks of life in our country, and new media's growing popularity, our production and daily life become more convenient, especially the network technology continues to progress, which makes the public daily life is more convenient, we do not go outside, we can finish tasks and operation, such as online booking, reservation and so on. To a certain extent, it improves people's life, with the new media continues to spread, the demand for other aspects of the public is also growing, such as computer animation industry. In recent years, the rapid development of China's animation industry is called "sunrise industry", in the new media environment, China's computer animation production technology continues to reform, continues to launch new products, attracts the attention of the public, and promotes the development of animation industry for a long time.

\section{Application of 3D animation technology}

\section{Basic overview}

With the rapid development of computer technology, the field of animation has been changed, in the basis of the two-dimensional animation, after continuous innovation to form three-dimensional animation, and three-dimensional animation, in a certain sense, can be called 3D animation. It is roughly divided into three stages: the early stage, including the script creation, modeling design, scene design, sub lens design, the middle stage, including role setting, 3D modeling, specifying material, production mapping, binding bone and adjust the action, setting the light source, setting camera, rendering, etc., the last stage, including two dimensional effects and post synthesis. For example the recent release of the movie "catch demon" in Huba animation image and "the return of the saint", the saint image that uses means of 3D image setting and operation. In Figure two or three, and figure four, which show us the production process 3D movie "King image".

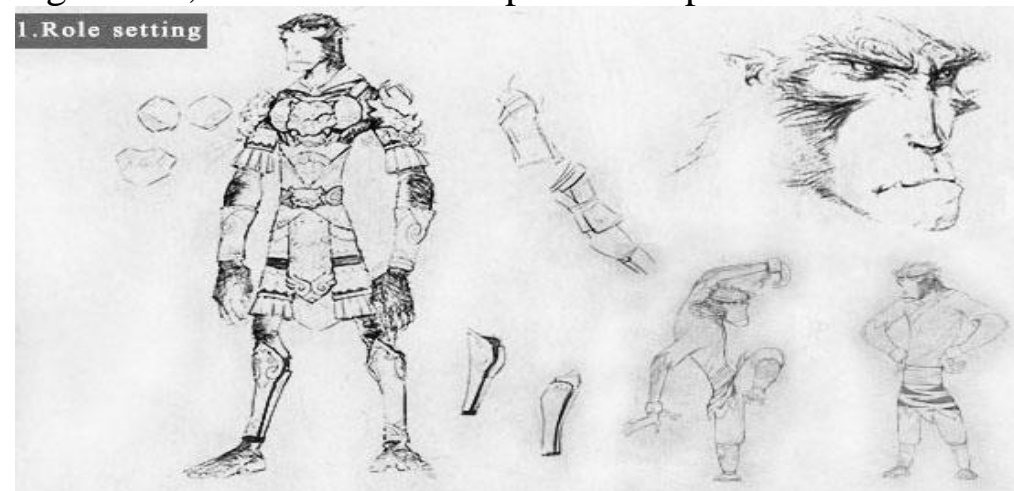

Figure 2 mahatma's image in the film "the return of another $3 \mathrm{~d}$ characters of production process 


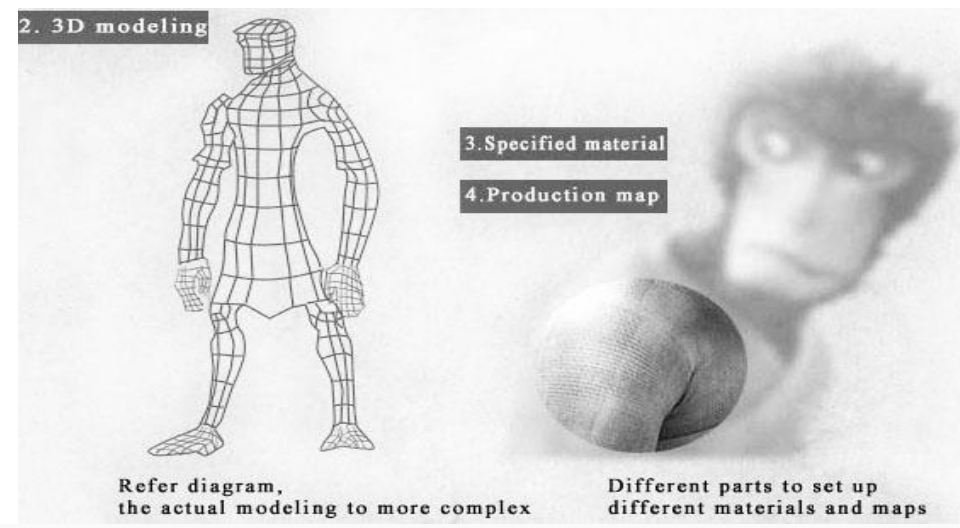

Figure 3 the film "the risk return of three-dimensional mahatma's image in the role of production process of 2, 3, 4

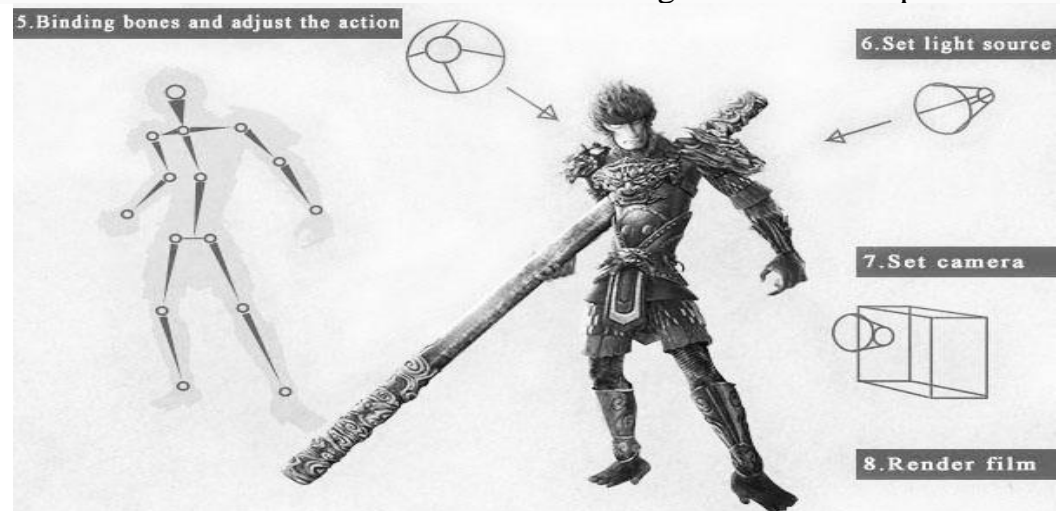

Figure 4 mahatma's image in the film "the return of another $3 \mathrm{~d}$ production process for the role of 5, 6, 7, 8

\section{development advantages}

3D animation technology and other traditional animation technology have some advantages as follows: First, the three-dimensional animation technology has a lot of operating functions, the performance of many lens is unique, and the two dimensional technology is impossible to achieve comparing with the three-dimensional animation technology. Second, comparing to the two-dimensional animation technology, three-dimensional animation technology has a strong modification. In a certain sense, it makes the animation image more characteristic. Third, the three-dimensional animation technology has a very strong simulation function, for the animation scene in the special effects, in which it can not be achieved, can be achieved simulation with three-dimensional animation technology. Fourth, the visual aesthetic effect of three-dimensional animation is good, that is real, detailed, natural, and about the animation set, three-dimensional animation technology can make it become more beautiful, more smart, in a certain sense, it can attract more people to watch, for example: now the 3D film is more and more popular, and it is due to the flexible use of technology. Fifth, the three-dimensional animation technology in the production process, the cost of the production process is low, and the production cycle is short, and in the creation of the animation image, in fact, is a very good combination of two aspects that is hardware technology, human technology, which is not achieved in the traditional two-dimensional technology.

\section{Development characteristics}

\section{Strong model building}

In the development of animation industry, due to the restricted by many factors, such as photographing, hand drawn animation and so on, the designer's design is often limited, can not follow one's inclinations during creation, and can not switch freely in illusion. In view of the above situation, 3D animation technology after continuous development and evolution, in a certain sense, it realized the goal, in the creation of 3D animation, not only can create vivid characters, but also can be free to switch the actual situation of the scene and beautiful scenes, and real life scenarios such as a rut: for example, it many costume drama selection of this technology. Most recently hit series "Scene" in the flower and bone is from 3D animation technology. In the creation of animation scene designers with tools, line, plane geometry, through computer software, drawing objects simulation, can scarcely be distinguished from natural flowers. 


\section{Free application}

With the helping of 3D animation technology, the objects can be randomly oriented, but also can control the direction of the movement trajectory, and can change the angle of observation, therefore, three-dimensional animation technology is more and more respected, its without binding can be reflected in the bottom surface:First, the 3D animation design can show some disembodied things or objects, such as "the Lord of the rings" in the fairy queen and her on a pool of still water spell, hydrostatic morphological changes, become a mighty force of the Navy. This is an illusory scene, in real life can not be achieved.Secondly, it can achieve the continuity shooting, from the microscopic world, gradually turned to the macroscopic world, this continuous shooting style, if we use a common approach simply can not be achieved, but if using the 3D technology will be able to get a good shot.

\section{The application of Flash animation technology}

When 3D animation team in traditional animation broadcast field wants to break the ice and out, flash has on the emerging network media and mobile phone set off a frenzy of personal animation. The threshold of making these animations is very low, often several people even one person can completed all the tasks. The idea is endless. These FLASH can provide the reference for the television animation material and market reaction, and it also can be directly put on the TV broadcast.

\section{Flash animation features}

First, for the Flash animation technology, it's relatively small size, but by the combination of some elements, showing the animation effect is amazing. Second, Flash technology can be used for advertising, and because of its smaller size, so the application range, regardless of which site can be achieved, not only its application range is constantly changing, also can be used for radio and television, and for each kind of new media, such as mobile phones, networks, micro channel, etc., can be carried out Flash advertising. Third, the flash technology to the fusion of a variety of elements, with the helping of these elements made of the advertising, has strong consensual and such works tend to be more likely to attract the public. Fourth, Flash in the network platform has a strong skill of communication, which is based on the design of the web page, and its carrier is vector animation, the method is relatively simple, that is, the vector operation, the film space, to a certain extent, controls the film storage space. While the format of the file is relatively special, but it can be played by any player, and it can also be transformed into the work, the document is set to a certain form that is exe format, so you can browse on the computer, and do not need to install Flash player. Fifth, under application in process of Flash animation technology, it has a variety of forms, and it meets the different needs of the masses of animation effects, showing a strong affinity, to achieve a mutually beneficial, in the maximum, the formation of their own visibility, so that the majority of people to their understanding of the more in-depth.

\section{mobile media applications}

With the new media continues to spread, the new media gets some related support, such as mobile phones, it can be the most representative of the new media, and Flash animation, its mobile media has also been very good application, and the application of the mobile media, Flash animation technology, to some extent, promotes the mobile media business, and mobile phone has a large range of applications, so Flash animation technology, which can achieve good communication effect. It can be predicted that there will be a great market after outputting the media of mobile phone animation.

\section{application of digital technology \\ Online game development}

Under the new media environment, digital animation technology has been more used widely, and it plays a great role in the network game, and it is also the most applied place, in the development of China's online games, digital animation technology has played an important role in promoting function. In the online games, all things involved, including the scene, characters, equipment, and so on, designers in the design, using all the equipment are relying on the digital animation technology to complete, and its showing the effect of life, to bring fans a visual impact. 


\section{Applied to news events}

News is a kind of documentary reports, especially mainly for the recent events, the system reports, which not only requires the timeliness, but also to the authenticity of certain requirements. In many cases, based on the above requirements, some of the reports are too heavy, and the content is more boring, and some news reports, the people can not understand the phenomenon of the occurrence of. At this time, the news reports can use digital animation technology, but the public's understanding of digital animation technology is still at a certain level, it is only a virtual technology, and therefore, it is difficult for the public to contact the documentary. However, the fact is often different, animation is not only a kind of virtual technology, but also can be a documentary expression. In the content of the news, there is often no visual content, can not directly show the report, but must be expressed in the content, so you can use the digital animation technology to restore the event scene. For example: car accident simulation diagram, due to the scene of the accident is too bloody, and it does not show directly, so in news reports, we often use virtual, animation, in the form of animation display, talking about what the ins and outs of story.

\subsubsection{Applied to the protection of cultural relics and cultural dissemination}

The use of modern digital technology in the world heritage project to show the full range of cultural heritage, through the cultural heritage of the digital heritage will be better protected. For example, in the Mogao Grottoes of Dunhuang digital display center by digital technology to build the ball screen movies "dream team", the Mogao Grottoes exquisite murals and sculptures full range realistically show in front of audiences.

\section{The development trend of computer animation in the new media environment}

With the rapid development of the animation production technology, the communication of new media such as network, mobile phone and so on, and a new field has been opened. The new media animation is based on the digital technology as the core, with "optical" and "electronic media" as the basic language of animation form. New media animation works with visual, auditory, tactile, physiological and psychological comprehensive effects. Computer animation is no longer limited to narrow animation, but from the animation industry to animation industry, animation and new media will have a huge impact. New media, animation, to mobile phones, mobile TV, network, digital TV, digital cinema, touch media platform to show the audience the animation form, including series animation, comics, mobile phone theme, mobile phone animation, facial expressions and so on, with the application of IPTV and digital TV, 4G technology and spread of the tremendous business opportunities in the animation business, the new media market size should not be overlooked. According to CNNIC released the thirty-fourth times of "China Internet development statistics report" shows in June 2014, China's Internet users reached 632,000,000, of which mobile phone users reached 527,000,000, Internet users in the use of mobile Internet users accounted for $83.4 \%$ of the first time beyond the traditional PC (personal computer) Internet users scale, the latter is $80.9 \%$. In the face of the sea like capacity of the market, the new media has become a good opportunity for Chinese animation development, the new media is the development of China's animation accelerator and catalyst. Now, as the representative of the new media animation has been developed into the new media animation industry has become a new growth point.

China's animation industry has experienced 3 times of revolution in total: the first time is based on the traditional paper publications and traditional art animation film; the second is based on Japan and the United States' television animation, books, derivative products integration of the content + commodity industry model; the third is the new media animation as the representative of the new media animation. In the future, the development trend of the media is highly interactive, it is no longer a simple content of a single production. And its spread will be more extensive, especially after the integration of game and other things, there will be a variety of interactive game playing ways. New media animation prospects will be very good, and even it may be about the overall trend of the animation industry development, in the future it will be the main force of animation development. 
With promotional channels of the Internet, mobile Internet, mobile TV, mobile TV, electronic magazines, digital TV and other channels, which make the traditional new media animation products more accurate, it can effectively cover to the main audience, and it can establish "a new media platform, and building cross platform animation brand promotion mode" to creative work as the center, to actively promote creative and technology integration, to create a series of creative brand, and to seize the commanding point of creative industry development, it will integrate creative talent, information, technology, capital and other factors, to further expand domestic and foreign markets, and to create a complete creative industry chain.

\section{Summary}

In summary, along with the new media, it has been applied in many fields. And in the new media environment, computer animation technology has also been a better application, and promote its application range, moreover it relates with people's production and life more closely, to a certain extent, it will promote social and economic development, at the same time, due to the transformation between the computer animation technological system, will let the public feel the visual impact, and thus further get more affection and good feeling among the public. The combination of new media and animation will be a new industry. Just seizing the opportunity, it will make China's animation industry to take off again.

\section{References}

[1]Yang shien. The three dimensional animation production combined with virtual reality technology research[J]. Micro computer and application,2011(15).

[2]Guo Wei,Lan Jingting. The three dimensional animation and motion capture technology [J]. Journal of sichuan liberal arts college,2011(05).

[3] ]Guo Wei, Lan Jingting, Feng zhuqing. The three dimensional animation and motion capture technology [J]. Film and television production,2011(11).

[4]Lijinjie, Tao dongxiang, Chen Hong.3Danimation technology in the application of the multimedia teaching software manufacture[J]. Science and technology information,2013(17).

[5]Gao wenming. The 3ds Max animation technology exquisite course construction and reform [J]. Computer CD software and application,2013(12).

[6]Shao guohong. Methods to explore Flash plane animation technology [J]. Digital technology and application,2014(09).

[7]Jing xuefei, Song lixin. Under the new media art classification of animation research and development trends [J]. Art and design (theory),2010(05).

[8]Li Yuan. The method of animation research under the new media environment [J]. Art education,2015(06).

[9]Han yawei, Shu Hou, Li shuofei,Qian hongbing. "Micro $3 \mathrm{~d}$ animation" under the new media environment[J]. Digital technology and application,2014(02).

[10]http://news.xinhuanet.com/video/sjxw/2015-08/06/c_1116159007.htm[EB/OL].

[11]http:/www.comicyu.com/html2012/145/2015/169903.html[EB/OL].

[12]http://comic.people.com.cn/GB/122400/130243/14668831.html[EB/OL]. 